\title{
NMR metabolomics revealed metabolites and bioactivity variation in Torbangun leaves Plectranthus amboinicus L. with different origins
}

\author{
Nancy Dewi Yuliana ${ }^{1,}$, , Muhammad Anwari Sugiharto $^{1}$, Hanifah Nuryani Lioe $^{1}$, Masao Goto $^{2}$, and Yuko Takano Ishikawa ${ }^{2}$ \\ ${ }^{1}$ Department of Food Science and Technology, Faculty of Agricultural Engineering and Technology, Bogor Agricultural University, IPB \\ Dramaga, Bogor 16680, Indonesia \\ ${ }^{2}$ Functionality Evaluation Unit, Food Function Division, Food Research Institute, NARO, Tsukuba-Ibaraki, Japan \\ *Corresponding author: nancy_dewi@ipb.ac.id
}

SUBMITTED 8 September 2018 REVISED 27 November 2018 ACCEPTED 11 December 2018

\begin{abstract}
Plectranthus amboinicus has been reported to have antidiabetic and antioxidant activities. Environmental factors might influence the plant's secondary metabolite profile and its beneficial properties. NMR-based metabolomics was used to show phytochemical variations between specimens of $P$. amboinicus grown in Japan and Indonesia. The results showed that flavonoids and triterpenes were among the discriminating factors of the variation between the two groups. Targeted comparative analysis of the concentration of the specific flavonoids of the plants using a validated HPLC-MWD method showed that the Japanese samples contained a higher concentration of total flavonoids compared with the Indonesian samples. The Japanese and Indonesian samples contained 1100.6 \pm 5.1 and 532.4 $\pm 1.8 \mu \mathrm{g} / \mathrm{g}$ luteolin, and 584.5 $\pm 7.4 \mathrm{and} 571.7 \pm 11.6 \mu \mathrm{g} / \mathrm{g}$ apigenin, respectively. Eriodyctiol was detected only in the Indonesian samples. Contrarily, more intensive DPPH reduction and $\alpha$-glucosidase inhibition activities were found in the Indonesian samples (IC $5014.4 \pm 1.2$ and $24.0 \pm 0.3 \mu \mathrm{g} / \mathrm{mL}$ for the DPPH assay, $1181.9 \pm 113.5$ and $4451.4 \pm 290.0 \mu \mathrm{g} / \mathrm{mL}$ for $\alpha$-glucosidase inhibition, respectively). Thus, flavonoids might not be the only group of compounds related to the aforementioned bioactivities. This should be confirmed by further research targeting other groups of compounds, such as triterpenes.
\end{abstract}

KEYWORDS antidiabetes; antioxidant; flavonoids; metabolomics; Plectranthus amboinicus

\section{Introduction}

Plectranthus amboinicus is a shrub spread over tropical Africa, Asia, Australia, and South America, particularly Brazil (Lukhoba et al. 2006). Similar with mint, sage, and basil, it belongs to Lamiaceae family. It has several local names for examples Indian-borage, Indian-mint, French-thyme, Spanish-thyme, Oreille, and Karpuravalli. In Indonesia, P. amboinicus is known as Torbangun. The leaves are traditionally used as breast milk simulant (lactagogue) by Bataknese lactating women in North Sumatra (Damanik et al. 2006). Many compounds have been identified from P. amboinicus leaves (Brieskorn 1977; Brieskorn and Riedel 1977). The antihyperglycemic (Viswanathaswamy et al. 2011), and anti-inflammatory (El-Hawary et al. 2012) potential of the plant extracts were reported. Indeed, this pharmacological potential highlights the relevance of the plant in the treatment of increasingly relevant degenerative disease.

Variation of chemical composition of natural products may occur due to the variations in genotype, geographical origin, or post-harvest handling. These factors may significantly alter the efficacy of the plant functional properties (Wang et al. 2005). The same case might occur in P. am- boinicus which grows in different environment. Thus, it is important to assess the variability of $P$. amboinicus as raw materials to keep a final product quality consistency. For such a purpose, metabolomics is one of the most reliable methods. The use of NMR in metabolomics based works is preferable as attributed to its high throughput capability, reproducibility, and robustness. Various multivariate data analysis such as Principal Component Analysis (PCA) or Orthogonal Projection to the Least Square-Discriminant Analysis (OPLS-DA) is very helpful to interpret a huge metabolomics data and to find discriminating factors responsible for samples classification (Yuliana et al. 2011a).

This study focused on $P$. amboinicus secondary metabolites profiling, particularly flavonoid variation in specimens of $P$. amboinicus grown in Bogor (Indonesia) and Tsukuba (Japan). To the best of our knowledge, this is the first report of NMR-based metabolomics application combined with HPLC-MWD targeted analysis to reveal the phytochemicals differences between Indonesian and Japanese $P$. amboinicus. We firstly used ${ }^{1} \mathrm{H}$ NMR-based metabolomics to identify discriminating factors of both samples. For NMR-metabolomics study, instead of single solvent extraction, we applied comprehensive extraction technique consisting of a continuous flow of solvent mix- 
tures through powdered plant material placed in a metal column. The method is more suitable for metabolomics based works since it provides extracts with a wider chemical variety than those obtained from single solvent extraction (Yuliana et al. 2011b). The compounds marker was further quantified using validated HPLC-MWD technique. Antioxidant and $\alpha$-glucosidase inhibition activity of each samples were also determined in-vitro.

\section{Materials and methods}

\subsection{Plant materials}

Indonesian $P$. amboinicus were obtained from Kebun Percobaan Mulyaharja, Bogor and authenticated by Prof. Muhammad Rizal Martua Damanik from Bogor Agricultural University. Japanese $P$. amboinicus were obtained from Tsukuba Botanical Garden and authenticated by Dr. Tomohisa Yukawa from Tsukuba Botanical Garden. Samples were collected in August 2015. The leaves grew about $10 \mathrm{~cm}$ from the tip of shoots and were free from blemish and defect were chosen and immediately stored at $-20^{\circ} \mathrm{C}$ until lyophilized (neither washed nor chopped to avoid browning due to friction of short-hair on leaves). The frozen leaves were lyophilized for $48 \mathrm{~h}$ with a freeze dryer (FreeZone 6 l Console Freeze Dry System, Labconco, Kansas City, MO), the dried leaves were crushed to 30 mesh powder. The leaves were stored at $-20^{\circ} \mathrm{C}$ in sealed aluminum bags until analysis.

\subsection{Chemicals}

The chemical reagents that were used are all pro-analytical grade, and are as follows: double-distilled water, hydrochloric acid ( $\mathrm{HCl}) 37 \%(12.0 \mathrm{M})$, tetrahydrofuran, acetonitrile, methanol, phosphoric acid, potassium acetate, aluminum (III) chloride, 1,1-diphenyl-2-picrylhydrazyl (DPPH), $\alpha$-Glucosidase (from Saccharomyces cerevisiae type I), and $\alpha$-D-glucopyranoside, along with apigenin, luteolin, and eriodictyol standards. Analytical grade or standard grade of chemicals were used in this study. Methanol washed sea sand with 20-35 mesh size, acetone and nhexane were from Wako Pure Chemical Industry Ltd., (Osaka, Japan). MeOH-d6 was from Cambridge Isotope Laboratories, Inc.(MA, USA). Double-distilled water was obtained from PT Ikapharmindo Putramas (Jakarta, Indonesia) while the rest of the chemicals used in this research were obtained from Sigma-Aldrich (St. Louis, MI, USA).

\subsection{Methods}

\subsubsection{Flavonoids extraction}

Sample extracts used for the DPPH and $\alpha$-glucosidase assays were obtained by extraction using a Dionex ${ }^{\mathrm{TM}} \mathrm{ASE}^{\mathrm{TM}}$ 350 Accelerated Solvent Extractor system (Thermo Fisher Inc.) with methanol as the extraction solvent. The method of sample extraction and hydrolysis for HPLC analysis was done according to a method from previous study (Lin et al. 2007).

\subsubsection{Comprehensive extraction for metabolomics study}

Comprehensive extraction was conducted according to a previous study (Yuliana et al. 2011b), unless that the extraction was performed in a stainless steel column $(5.0 \mathrm{~cm}$ length, $2.0 \mathrm{~cm}$ diameter) and mixture which was packed to the column consisted of $1.0 \mathrm{~g}$ of dried powdered sample and $5 \mathrm{~g}$ of methanol-washed 20-35 mesh sea sand.

\subsubsection{NMR and multivariate data analysis}

The ${ }^{1} \mathrm{H}$-NMR measurements were performed using a 500 MHz Varian INOVA NMR spectrometer (Varian Inc., California, USA) functioning at frequency of $499.887 \mathrm{MHz}$ and maintained at $26^{\circ} \mathrm{C}$. NMR analysis was performed on all samples obtained from comprehensive extraction (90 samples). Solvent residue in all samples were evaporated using rotary evaporator and flushed under nitrogen gas for a complete dryness. The dried samples were dissolved in $1 \mathrm{~mL}$ of methanol- $d 4$, vortexed, centrifuged for $10 \mathrm{~min}$ (10000 rpm), and $800 \mu \mathrm{L}$ was pipetted from each samples and transferred into NMR tubes, then subjected for NMR analysis with a method described elsewhere (Mediani et al. 2012). Principal Component Analysis (PCA) and Orthogonal Projection to the Least Square-Discriminant Analysis (OPLS-DA) of NMR data were conducted using SIMCA$\mathrm{P}$ software version 14.0 (Sartorius Stedim Biotech, Umea, Sweden) with pareto scaling.

\subsubsection{HPLC-MWD instrument performance tests}

The HPLC analytical method was modified from an earlier developed methodology (Haghi and Hatami 2010) as follow: stock solutions of apigenin, luteolin, and eriodictyol were made by diluting the standards in $100 \%$ methanol and sonicating. Serial dilutions $(0.1-100.0 \mu \mathrm{g} / \mathrm{mL})$, using the mobile phase $(4.00 \%$ tetrahydrofuran in acetonitrile/0.20\% aqueous phosphoric acid, 35:65, v/v) as the solvent, of the stock solutions were then subsequently made and filtered using a syringe filter equipped with a 0.45-micron PVDF filter. Approximately $20 \mu \mathrm{L}$ of the standards were then injected into the HPLC equipment which have been equipped with a reverse phase ZORBAX Eclipse XDB-C18 column (150 x 4.60 mm i.d., particle size $5.00 \mu \mathrm{m}$, Agilent Technologies, USA). The mobile phase was isocratic and the flow rate was $1.0 \mathrm{~mL} / \mathrm{min}$ for $15 \mathrm{~min}$ at $28^{\circ} \mathrm{C}$. Apigenin and luteolin was measured at $340 \mathrm{~nm}$ while eriodictyol was measured at $290 \mathrm{~nm}$. The determination of the aforementioned flavonoid contents was performed simultaneously using an Agilent Technologies 1200 infinity series G1365D Multiwavelength UV-Vis Detector (Agilent Technologies, Waldbronn, Germany). The instrument limit of detection (LODi) and instrument limit of quantitation (LOQi) was determined by the signal to noise ratio $(\mathrm{S} / \mathrm{N})$, in which concentrations with $\mathrm{S} / \mathrm{N}$ values that were between 2 and 4 was determined to be the LODi while concentrations with approximately twice that were determined to be the LOQi. Precision of the instrumental performance was obtained by determining the standard deviation and relative standard deviation of the measurements. Concentrations were expressed as $\mu \mathrm{g} / \mathrm{mL}$. 


\subsubsection{Method orientation using HPLC-MWD}

Method orientation tests were performed by modifying the hydrolysis conditions, chiefly the acid concentration and length of hydrolysis conditions. The goal of this procedure is to determine the best parameters which could consistently provide the greatest yield. As previously stated, the parameters of hydrolysis involve three concentrations of hydrochloric acid ( $2 \mathrm{M}, 4 \mathrm{M}$, and $6 \mathrm{M}$ ) which were obtained by adding $12 \mathrm{M}$ of hydrochloric acid at various volumes. The addition of the acid was performed on $0.50 \mathrm{~mL}$ of the concentrated dried Indonesian leaves extract. The time in which the mixture was heated was 120, 180, 240, and $360 \mathrm{~min}$. The HPLC conditions (column, amount injected, solvent, running time, detector and wavelengths, and running temperature) were the same as that used in the instrument performance tests. Results were expressed as $\mu \mathrm{g} / \mathrm{g}$. Apigenin, luteolin, and eriodictyol standards were also subjected to similar conditions of hydrolysis and were used as a comparison.

\subsubsection{Method validation using HPLC-MWD}

Method specificity was determined by spiking the crude extract of the Indonesian leaves with analytes at various concentrations $(0.5-50.0 \mu \mathrm{g} / \mathrm{mL})$. Spiking of the crude extract was performed immediately before acid hydrolysis occurs. The parameters of hydrolysis were then obtained from the results of the method orientation tests. Acceptable results had to display clear separation between peaks of analytes within the chromatograms and that the area of the peaks were responsive to the amount of analyte spiked in the sample matrix. A calibration curve for the spiked samples was created in order to determine the method linearity. The following parts of the method validation tests utilized this calibration curve to interpolate the concentration of apigenin, luteolin, and eriodictyol within the sample matrix.

Method accuracy, precision, limit of detection and limit of quantitation was determined through the following procedure. Apigenin, luteolin, and eriodictyol were fortified into the sample matrix immediately before acid hydrolysis occurs. The analytes were to have a final concentration that is equals to ten times than their respective instrument limit of quantitation. The method is deemed accurate when the recoveries of the analytes met the criteria set by the AOAC (Latimer 2012). The recovery was obtained through Equation 1.

$$
\text { Recovery }=\frac{C_{2}-C_{0}}{C_{1}} \times 100 \%
$$

in which $\mathrm{C}_{0}$ denotes the concentration of the analytes of unspiked samples, $\mathrm{C}_{1}$ denotes concentration of the analyte spiked in the sample matrix, and $\mathrm{C}_{2}$ denotes the concentration of the analytes in the spiked sample matrix. Acceptability of the method precision was determined through the relative standard deviation and Horwitz relative standard deviation values of the recoveries. Method limit of detection was determined by multiplying the standard deviation of the concentration of the analytes in the spiked sample matrix by three while said concentrations was multiplied by ten in order to determine the method limit of quantitation. Measurements that were found to be below the limit of detection were deemed as noise.

Intralab reproducibility was determined by only modifying the time of analysis. Within a span of one-month, weekly injections of the unspiked Indonesian leaf extracts were performed. Acceptability of the results were determined by comparing the relative standard deviation with the Horwitz relative standard deviation.

\subsubsection{Application of validated HPLC-MWD method on dried Plectranthus amboinicus leaves}

Approximately $20 \mu \mathrm{L}$ of filtered hydrolyzed extracts (parameters of hydrolysis obtained from the method orientation tests) of P. amboinicus were injected into the HPLC column. The HPLC conditions used for the analysis was the same as that used in the instrument performance tests. The quantity of apigenin, luteolin, and eriodictyol were each expressed as $\mu \mathrm{g} / \mathrm{g}$ and was interpolated from the calibration curve obtained from the method validation tests.

\subsubsection{Total flavonoid content of dried Plectranthus am- boinicus leaves using spectrophotometer-UV/Vis}

Analysis of total flavonoid was conducted according to a previous study (Chang et al. 2002).

\subsubsection{In-vitro pharmacological analysis of dried Plec- tranthus amboinicus leaves}

All samples from comprehensive extraction (90 samples) were evaporated using rotary evaporator to remove solvent residue. The dried samples were dissolved in 500 $\mu \mathrm{L}$ DMSO and then the pharmacological properties (antioxidative and $\alpha$-glucosidase inhibitory activities) were analyzed. Both assays were carried out in accordance to previously reported methods (Shibano et al. 1997; SalazarAranda et al. 2011).

\subsubsection{Statistical analysis}

Statistical comparisons between data was performed using one-way ANOVA at 95.0\% confidence levels. Significance values that were found to be less than 0.05 indicated statistical difference. Tukey HSD post-hoc tests were also performed when applicable. Precision of measurements was determined by determining the relative standard deviation (RSD) and the Horwitz relative standard deviation $\left(\mathrm{RSD}_{\mathrm{H}}\right)$ when applicable. The Horwitz relative standard deviation was calculated using Equation 2.

$$
R S D_{H}=2^{1-0.5 \log C}
$$

where $C$ is the average of one set of measurements expressed as mass fraction. Acceptable repeatability was indicated by the RSD value of a dataset being less than its corresponding RSDH value. When it was not possible to determine the RSDH value of a dataset, acceptability of the precision of said dataset was determined solely by its RSD value, in which values that are less than 5\% was deemed acceptable. 


\section{Results and discussion}

\subsection{Chemical Variability of Indonesian Plectranthus amboinicus and Japanese Plectranthus amboini- cus}

In this study we compared the chemical variability of $P$. amboinicus grown in two different geographical regions. Indonesian P. amboinicus was cultivated in Bogor, which is located at $6^{\circ} 35^{\prime} 48^{\prime \prime} \mathrm{S}$ latitude-106 $46^{\circ} 50^{\prime \prime} \mathrm{E}$ longitude, $265 \mathrm{~m}$ above sea level. The annual average temperature and humidity are $26^{\circ} \mathrm{C}$ and $70 \%$, respectively. Bogor has a significantly high annual rainfall, 3500-4000 mm with the highest is in December and January. The sunshine duration percentage is quite varied, ranging from 30 to $70 \%$, with the highest occurring in August and the lowest in January. Japanese $P$. amboinicus was grown in Tsukuba which is located at $36^{\circ} 5^{\prime} 0.5^{\prime \prime} \mathrm{N}$ latitude- $140^{\circ} 4^{\prime} 35.2^{\prime \prime} \mathrm{E}$ longitude, $33 \mathrm{~mm}$ above sea level. Compared with Bogor, Tsukuba has a lower annual rainfall (1282 mm), lower average annual temperature $\left(13.8^{\circ} \mathrm{C}\right)$, and lower average humidity (62\%). Morphological differences between Indonesian P. amboinicus and Japanese P. amboinicus are mainly observed in the leaves. Indonesian $P$. amboinicus leaves are larger and thinner leaves compared with those of Japanese P. amboinicus.

There are in total $90 \mathrm{NMR}{ }^{1} \mathrm{H}$ spectra of Indonesian $P$. amboinicus and Japanese P. amboinicus fractions ob- tained from comprehensive extraction, thus it is not possible to show all the spectra. We chose fraction 8 from each group as representative spectra which is presented in Figure 1. The spectra was scaled to the highest peak (MeOD) intensity. It is shown that the area of $\delta$ 5.0-8.0 in Japanese $P$. amboinicus NMR spectra had a higher intensity than those of Indonesian P. amboinicus. While Indonesian $P$. amboinicus has a higher intensity of $\delta 0.5-1.8$ area. It is very difficult to extract information from all 90 spectra only by visual obsevartion. We further converted all 90 spectra into ASCII files and analyzed them using multivariate data analysis (PCA and OPLS-DA) to find chemical shifts differences between the two groups.

The results of PCA analysis is presented in Figure 2. The PCA score plot showed that the most non-polar fractions obtained from $n$-hexane $100 \%$ which represented as fraction A1, B1, and C1 which belonged to Japanese $P$. amboinicus group, and IND 1A, IND 1B, and IND 1C which belonged to Indonesian $P$. amboinicus group, were classifed seperately in circle 1 . It indicated that they have quite different chemicals profile. Other differences were observed in the grouping of relatively polar fractions (fraction $8,9,10,11,13,14$ and 15 , which come acetone $100 \%$ and a mixture of acetone with water at different composition). This group is marked as circle 2 (Figure 2a). Other fractions with medium polarity were not so much different from each other, shown by almost overlapping posi-

(a)

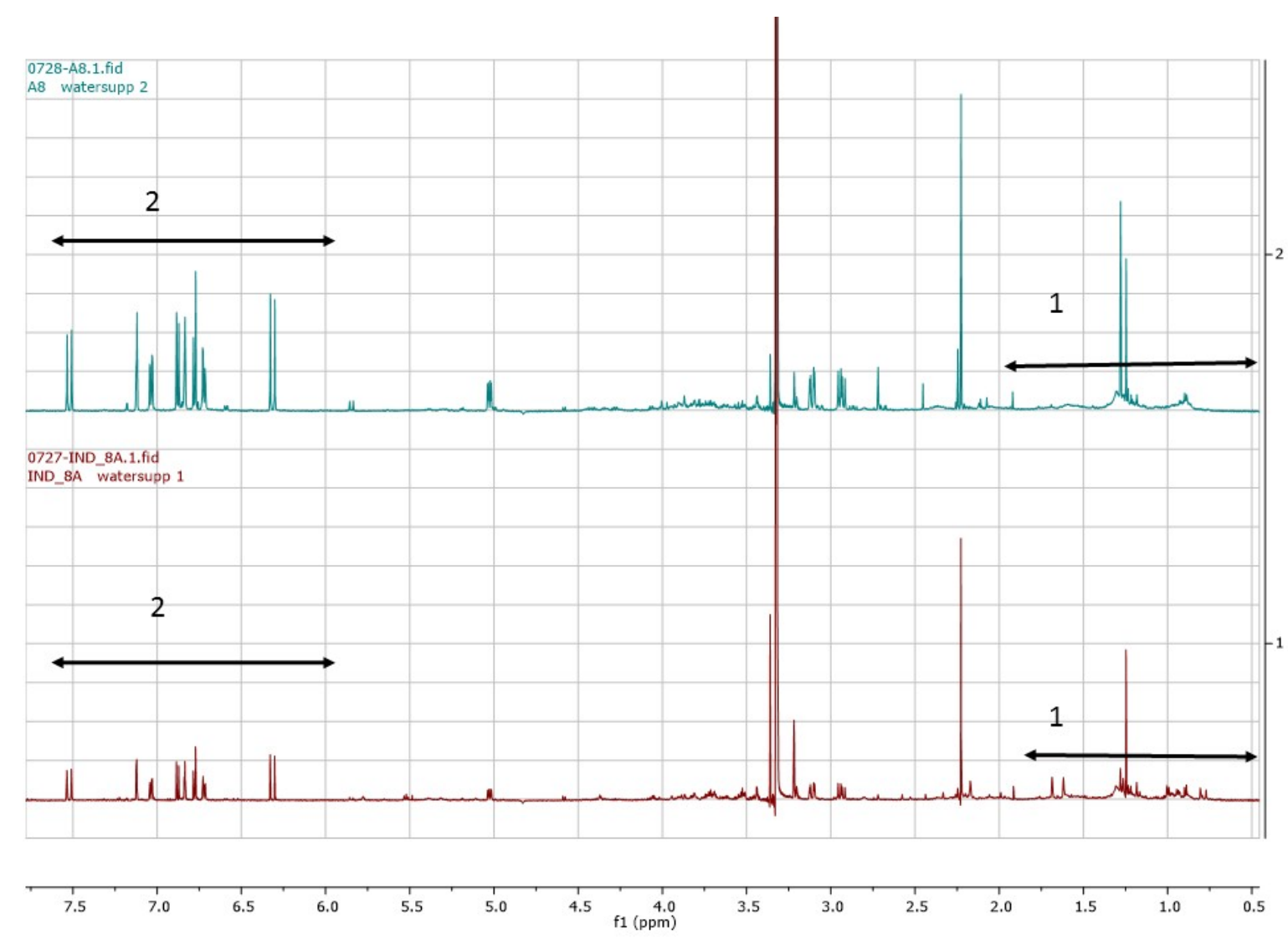

FIGURE 1 Representative ${ }^{1} \mathrm{H}$ NMR spectra of Japanese P. amboinicus (a) and Indonesian P. amboinicus (b) fraction 8 , representing fraction with medium polarity. The visible differences between spectra were observed at of $\delta 0.5-1.8$ area (1) and $\delta 5.0-8.0$ area (2). 


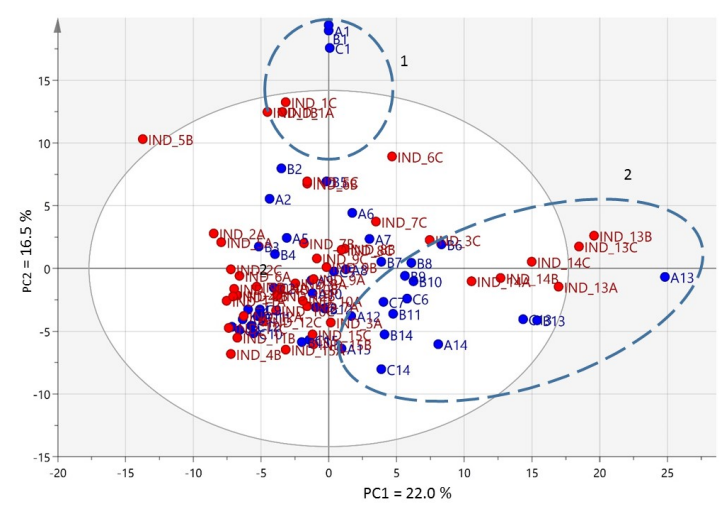

(a)

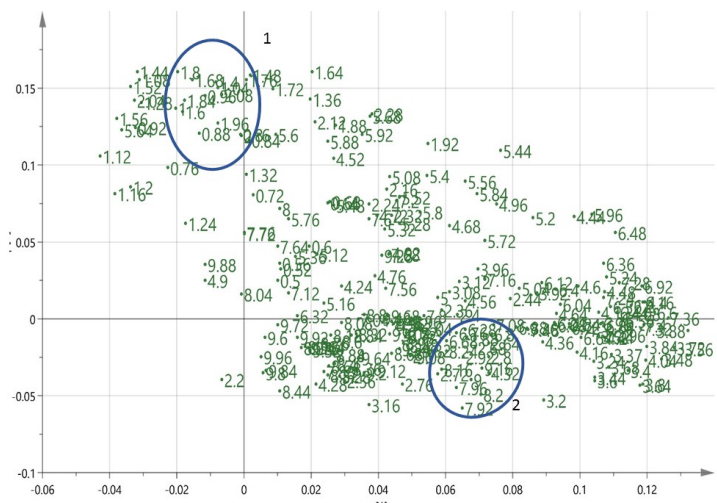

(b)

FIGURE 2 PCA score plot of Indonesian P. amboinicus (IPA) and P. amboinicus (JPA) obtained from comprehensive extraction. The red and blue dots representing different sample origin (Red dot with IND_A1-IND_C15 labels are Indonesian samples, Blue dots with A1-C15 are Japanese samples). The letter A, B, and C representing extraction replication, the number 1-15 representing low to high polarity extraction solvent ( $n$-hexan-acetone-water in gradient, see extraction scheme in Materials and Methods section).

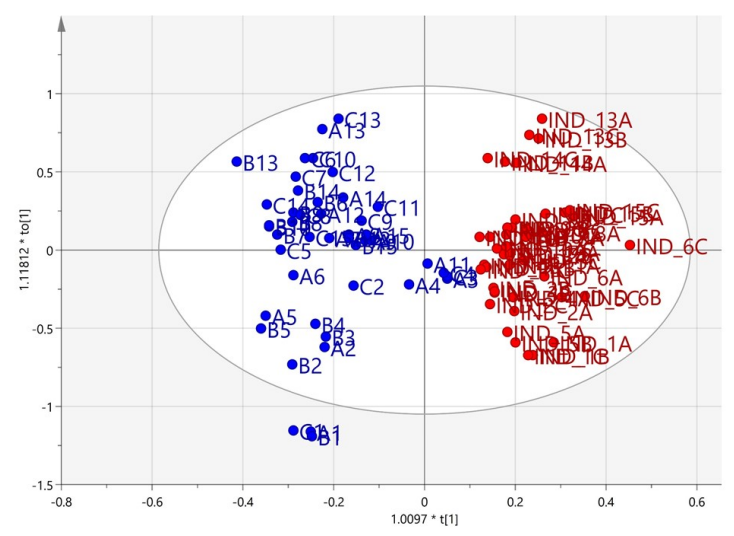

(a)

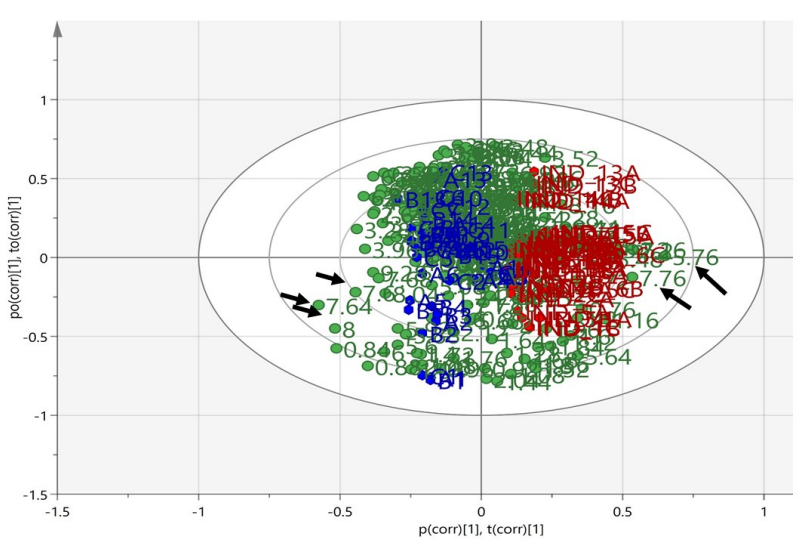

(b)

FIGURE 3 (a) OPLS-DA score plot of NMR data of Indonesian P. amboinicus (IPA) and Japanese P. amboinicus (JPA); (b) OPLS-DA loading biplot NMR data of Indonesian P. amboinicus (IPA) and Japanese P. amboinicus (JPA). The red and blue dots representing different sample origin (Red dot with IND_A1-IND_C15 labels are Indonesian samples, Blue dots with A1-C15 are Japanese samples). The letter A, B, and C representing extraction replication, the number 1-15 representing low to high polarity extraction solvent (n-hexan-acetone-water in gradient, see extraction scheme in Materials and Methods section).

tions for those fractions close to the center of the plot. In the loading plot (Figure 2b), it can be seen that chemical shifts at saturated alkanes area (e.g. $\delta 0.88,0.92,1.96)$ are discriminating factor for group 1 (very non-polar group), where as some chemical shifts at aromatic area (e.g. $\delta$ $6.60,7.60,7.90,8.20)$ are among discriminating factors for group 2 (polar group).

PCA is the first-pass method to identify chemical differences between high-dimensional data measurements. If the PCA model has reliable performance, further analysis can be done using other multivariate method. The minimum acceptable value of $Q^{2}$ is 0.4 while in general $R^{2} X$ value close to 1 indicating a representative model (Eriksson et al. 2003). In this study, the PCA model has $R^{2} X$ and $\mathrm{Q}^{2}$ of 0.838 and 0.433 , respectively. Next, a supervised multivariate data method, OPLS-DA, was used to fine tune discrimination between Indonesian P. amboinicus and Japanese P. amboinicus. We classified the sam- ples based on their origins. The OPLS-DA score plot showed a clearer separation than the PCA, with $\mathrm{R}^{2} \mathrm{X}=$ 0.543 and $\mathrm{Q}^{2}=0.736$ (Figure 3a). Permutaton test with 100 permutations gave the value $\mathrm{R} 2=0.28$ and $\mathrm{Q} 2=-0.46$, while the value for $p$ CV-ANOVA was $5.95 \times 10^{-19}$. All these validation value showed that the OPLS-DA model is reliable (Eriksson et al. 2003). Identification of NMR signals responsible for the two groups separation was undergone using OPLS-DA loading bi-plot (Figure $3 \mathrm{~b}$ ). There are two groups of NMR chemical shifts which attributed to the separation of Indonesian P. amboinicus and Japanese P. amboinicus. The first group is typical NMR chemical shifts for aromatic regions of flavonoids structure which are singlets, doublets, or double of doublets located between $\delta 6.00-\delta 8.00$ (see black arrows in Figure 3b). Some of these aromatic signals are found to be abundant in Indonesian $P$. amboinicus group and some are in Japanese P. amboinicus group. Previous studies reported that sev- 
eral flavonoids were identified in $P$. amboinicus, such as crisimaritin, eriodyctiol, apigenin and luteolin (Brieskorn and Riedel 1977; El-Hawary et al. 2012; Arumugam et al. 2016). The second group was typical chemical shifts for pentacyclic triterpenes, for example signals of tertiary methyl group (appeared as singlet at $\delta 0.84, \delta 0.88, \delta$ $0.96, \delta 1.12$, and $\delta 1.16$ ) and signals of an olefinic protons (around $\delta 5.00-\delta 5.50$ ). Indeed previous studies reported the presence of some flavonoids and triterpenes in this plant, such as oleanoic acid, ursolic acid, and maslinic acid (Brieskorn 1977; Brieskorn and Riedel 1977).

We compared the NMR data with those of the literatures and decided to focus only to eriodyctiol, apigenin and luteolin content of the plants since these three flavonoids were among the compounds previously identified in $P$. amboinicus as discussed before. The presence of eriodyctiol was detected in Indonesian P. amboinicus only (Figure 4). ABX splitting pattern in aromatic region which are characteristic of a 1,3,4-trisubstituted benzene ring appeared at $\delta 6.99$ (dd, $J 6^{\prime}, 5^{\prime}=8.5 \mathrm{~Hz}, J 6^{\prime}, 2^{\prime}=3.4 \mathrm{~Hz}$ ) (no. 5 in the Figure 4$)$. The two other signals which were reported as doublets at $\delta 6.79\left(\mathrm{J5}^{\prime}, 6^{\prime}=8.5 \mathrm{~Hz}\right)$ and $\delta 6.77\left(\mathrm{~J}^{\prime}, 6^{\prime}\right.$ $=3.4 \mathrm{~Hz}$ ) seemed to be a bit shifted and overlapped since we worked with a spectra of a crude or half-fractionated extracts . These two peaks could be attributed to the overlapping doublets appeared at $\delta 6.72$ and $\delta 6.73$ with the same coupling constant (no. 3 and 4 in Figure 4). Two meta-coupled doublets at $\delta 5.84(\mathrm{~d}, J 6,8=2.1 \mathrm{~Hz})$, and 5.87 (d, J8,6 = 2.1 Hz) (no. 1 and 2 in Figure 4) were also identified as small overlapping signals (Hameed et al. 2018). In OPLS-DA coefficient plots, all these signals had positive value in Indonesian $P$. amboinicus group but negative value in Japanese $P$. amboinicus (plot not shown). All these signals were identified in ${ }^{1} \mathrm{H}$ NMR spectra of Indonesian P. amboinicus fraction 6C (Figure 4) but absent in Japanese P. amboinicus fraction 6C (data not shown). Similar approach was used to identify luteolin and apigenin by comparing the spectra to previously reported data (da Silva et al. 2015).

\subsection{HPLC-MWD instrument performance tests}

To quantitatively measure the content of the abovementioned flavonoids, a validated HPLC based analysis was developed. However, the different spectral properties of flavonoids due to their varying structures poses a problem in their detection when using the commonly used

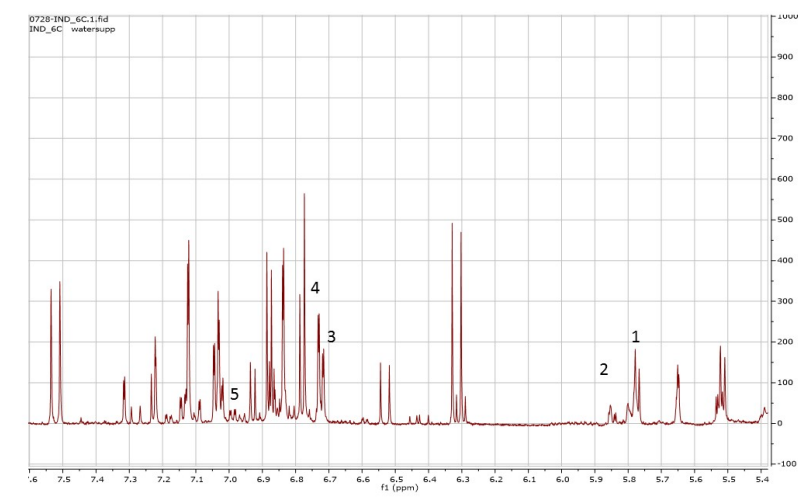

FIGURE 4 Representative ${ }^{1} \mathrm{H}-\mathrm{NMR}$ spectra containing typical signals for eriodyctiol. See text for detail explanation.

UV/Vis based detectors. Identification of flavonoids using standard UV/Vis detectors utilizes a single wavelength which in turn makes it difficult to simultaneously quantify target analytes with very contrasting spectral properties. Multiwavelength UV/Vis detectors (MWD) present an appealing alternative to standard UV/Vis detectors by eliminating the need to compromise on a single wavelength during the analysis.

The results of instrument linearity test was presented in Table 1. The peaks had adequate separation and the LODi was $0.1 \mu \mathrm{g} / \mathrm{mL}$ for all the flavonoids while the LOQi was $0.5 \mu \mathrm{g} / \mathrm{mL}$. Luteolin was the first analyte detected, with the shortest retention time of 3.893-3.947 min followed by eriodictyol at $4.108-4.152 \mathrm{~min}$, and apigenin at 6.169-6.266 min. The measured RSD of less than $1 \%$ for all the flavonoids indicates acceptable precision. The peak areas of luteolin and apigenin were higher in $340 \mathrm{~nm}$ compared with $290 \mathrm{~nm}$ and the inverse applies to eriodictyol (Figure 5). This is in accordance to the spectral properties of the flavonoids (Lin et al. 2007). In short, results of the instrument performance tests indicate that the HPLC equipment and its column were suitable for the simultaneous detection and quantification of the analytes.

\subsection{Method orientation using HPLC-MWD}

Method orientation tests were performed to determine the best combination of acid concentration and length of hydrolysis in terms of yield and consistency of achieving said yield. The aim of hydrolysis is to convert flavonoid gly-

TABLE 1 Instrument linearity of flavonoid standards measured using HPLC-MWD ${ }^{1}$.

\begin{tabular}{|c|c|c|c|c|c|c|}
\hline Flavonoid & Linear equation & $\mathrm{R}^{2}$ & Working range $(\mu \mathrm{g} / \mathrm{mL})$ & $\mathrm{t}_{\mathrm{R}}$ range $(\mathrm{min})$ & LODi $(\mu \mathrm{g} / \mathrm{mL})$ & LOQi $(\mu \mathrm{g} / \mathrm{mL})$ \\
\hline Apigenin & $y=108.8940+0.9903$ & 0.9999 & $0.1-100.0$ & $6.169-6.266$ & 0.1 & 0.5 \\
\hline Luteolin & $y=125.6661-68.1500$ & 0.9994 & $0.1-100.0$ & $3.893-3.947$ & 0.1 & 0.5 \\
\hline Eriodictyol & $y=129.0009-48.1248$ & 0.9999 & $0.1-100.0$ & $4.108-4.152$ & 0.1 & 0.5 \\
\hline
\end{tabular}

${ }^{1}$ Results were obtained using an HPLC-MWD in room temperature at $290 \mathrm{~nm}$ for eriodictyol and $340 \mathrm{~nm}$ for apigenin and luteolin. Separation was done using a Reverse-Phase ZORBAX Eclipse XDB- $C_{18}$ column (150 x $4.60 \mathrm{~mm}$ i.d., particle size $\left.5.00 \mu \mathrm{m}\right)$ The mobile phases were $4 \%$ tetrahydrofuran in acetonitrile (mobile phase $A$ ) and $0.2 \%$ aqueous phosphoric acid (mobile phase $B$ ) at a ratio of $35: 65$ (A:B). The flow rate was $1.0 \mathrm{~mL} / \mathrm{min}$ for $15 \mathrm{~min}$. Measurements were performed on diluted apigenin, luteolin, and eriodictyol standards. 


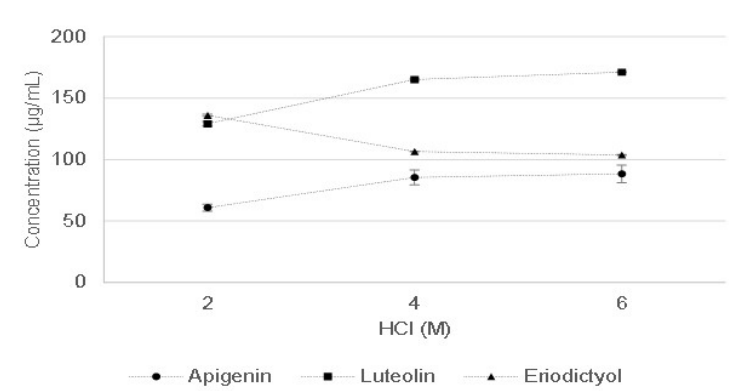

(a)

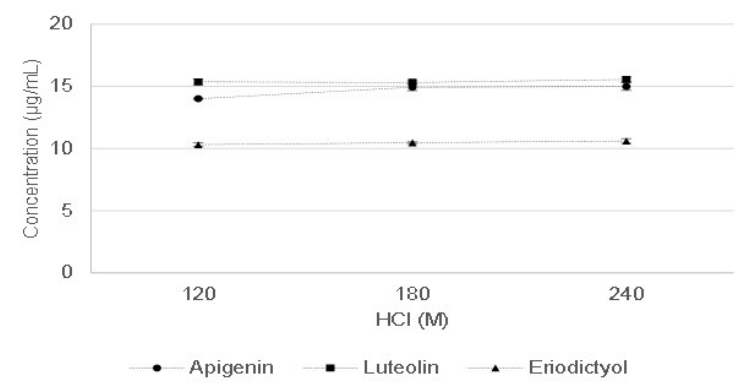

(c)

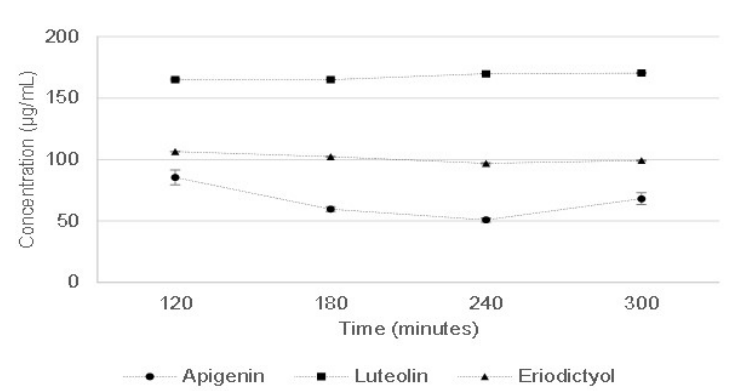

(b)

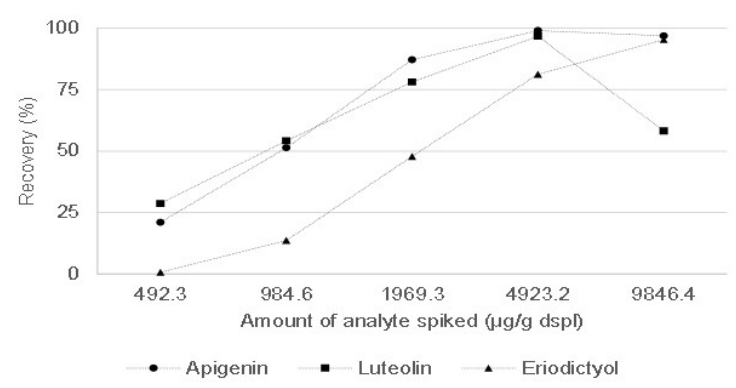

(d)

FIGURE 5 Apigenin, luteolin, and eriodictyol content in Indonesian Plectranthus amboinicus following hydrolysis at: (a) various $\mathrm{HCl}$ concentrations for 120 min at $85^{\circ} \mathrm{C}$; (b) various length of hydrolysis but at $4 \mathrm{M}$ of $\mathrm{HCl}$ and $85^{\circ} \mathrm{C}$. (c) Concentration of apigenin, luteolin, and eriodictyol standards following hydrolysis at different $\mathrm{HCl}$ concentrations for $120 \mathrm{~min}$ at $85^{\circ} \mathrm{C}$. (d) Recoveries of apigenin, luteolin, and eriodictyol in the sample matrix at various spiking concentrations. Measurements were performed using HPLC-MWD at $290 \mathrm{~nm}$ for eriodictyol and $340 \mathrm{~nm}$ for both apigenin and luteolin.

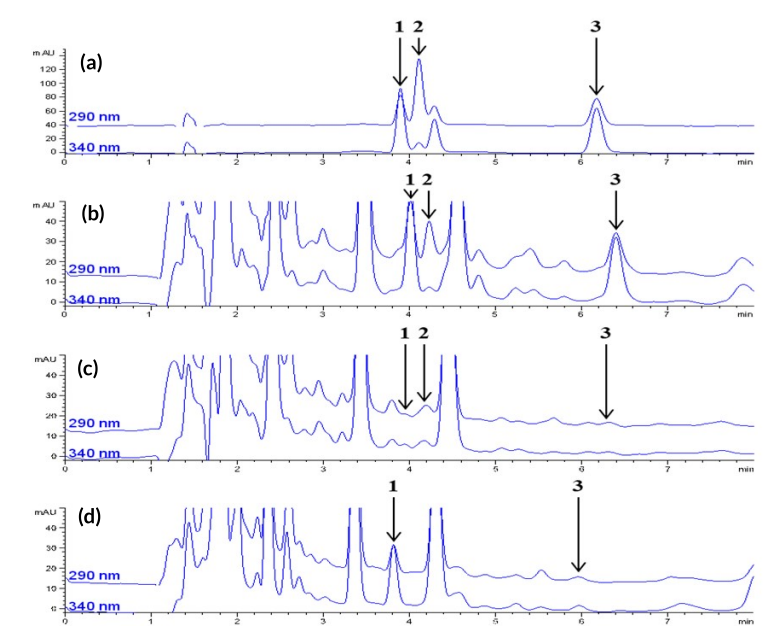

FIGURE 6 Chromatograms of apigenin (1), eriodictyol (2), and luteolin standards (3) at a concentration of $5 \mu \mathrm{g} / \mathrm{mL}$ solvent measured using HPLC-MWD at 290 and $340 \mathrm{~nm}$ (a). Indonesian Plectranthus amboinicus leaves spiked with $5 \mu \mathrm{g} / \mathrm{mL}$ solvent of apigenin, eriodictyol and luteolin and measured at $290340 \mathrm{~nm}$ (b). Unspiked Indonesian sample leaves measured at 290 and $340 \mathrm{~nm}$ (c), and unspiked Japanese sample leaves measured at 290 and $340 \mathrm{~nm}$ (d).

cosides into their aglycones. Hydrolysis of extracts using $4 \mathrm{M}$ and $6 \mathrm{M}$ of hydrochloric acid had resulted in greater apigenin and luteolin content compared to using only $2 \mathrm{M}$ of the acid. This increase in yield due to greater acid concentrations corresponds to a previous study on Indonesian P. amboinicus (Andarwulan et al. 2014). The stability of apigenin and luteolin standards at the different concentra- tions of hydrochloric acid (Figure 6a) suggested that the increase in apigenin and luteolin concentrations could be attributed to the hydrolysis of their glycosides. That being said, increasing RSD values had suggested that consistency was problematic for the analysis of apigenin in the dried leaves. Indeed, the RSD of the apigenin concentration was $8.96 \%$ when using $2.0 \mathrm{M}$ of $\mathrm{HCl}$ and had increased to $15.91 \%$ when using $6.0 \mathrm{M}$ of $\mathrm{HCl}$. Unlike apigenin and luteolin, the concentration of eriodictyol obtained from the dried leaves had decreased as the concentration of hydrochloric acid increased. However, the same was not observed in the eriodictyol standard therefore the destructive role of other compounds present in the extract, and their behavior during different levels of acidity must also be taken into consideration.

Increasing the length of hydrolysis had decreased the concentration of apigenin and eriodictyol obtained from the dried leaves. Conversely, the concentration of luteolin increased as the time went on (Figure 6b). In the end, the parameters of hydrolysis chosen was $2.0 \mathrm{M}$ of $\mathrm{HCl}$ at 120 min due to the relatively high eriodictyol yields and consistent apigenin yields (Figure 6c).

\subsection{Method validation using HPLC-MWD}

Method validation was performed by fortifying the concentrated unhydrolyzed dried leaf extracts with apigenin, luteolin, and eriodictyol at various concentrations. The spiked extracts were then subjected to hydrolysis using 2.0 $\mathrm{M}$ of hydrochloric acid at $85^{\circ} \mathrm{C}$ for $120 \mathrm{~min}$. Linearity of the method was determined by creating a calibration curve 
TABLE 2 Method linearity of flavonoid standards spiked in Indonesian Plectranthus amboinicus and measured using HPLC-MWD ${ }^{1}$.

\begin{tabular}{llccccc}
\hline Flavonoid & Linear equation & $\mathrm{R}^{2}$ & Working range $(\mu \mathrm{g} / \mathrm{mL})$ & $\mathrm{t}_{\mathrm{R}}$ range $(\mathrm{min})$ & $\mathrm{LOD}(\mu \mathrm{g} / \mathrm{mL})$ & $\mathrm{LOQ}(\mu \mathrm{g} / \mathrm{mL})$ \\
\hline Apigenin & $\mathrm{y}=119.0667 \mathrm{x}-114.4423$ & 0.9980 & $0.5-50.0$ & $6.032-6.283$ & 41.2 & 137.3 \\
Luteolin & $\mathrm{y}=132.9079 \mathrm{x}-169.4044$ & 0.9917 & $0.5-25.0$ & $3.839-3.963$ & 44.0 & 146.5 \\
Eriodictyol & $\mathrm{y}=98.9979 \mathrm{x}-294.9120$ & 0.9932 & $1.0-50.0$ & $4.030-4.175$ & 18.9 & 62.9 \\
\hline
\end{tabular}

${ }^{1}$ Results were obtained using an HPLC-MWD in room temperature at $290 \mathrm{~nm}$ for eriodictyol and $340 \mathrm{~nm}$ for apigenin and luteolin. Separation was done using a Reverse-Phase ZORBAX Eclipse XDB- $C_{18}$ column $(150 \times 4.60 \mathrm{~mm}$ i.d., particle size $5.00 \mu \mathrm{m})$ The mobile phases were $4 \%$ tetrahydrofuran in acetonitrile (mobile phase $\mathrm{A}$ ) and $0.2 \%$ aqueous phosphoric acid (mobile phase $\mathrm{B}$ ) at a ratio of 35:65 (A:B). The flow rate was $1.0 \mathrm{~mL} / \mathrm{min}$ for $15 \mathrm{~min}$. Measurements were performed on $20 \mu \mathrm{L}$ of hydrolyzed dried leaves extract of Indonesian Plectranthus amboinicus spiked with apigenin, luteolin, and eriodictyol prior to hydrolysis.

TABLE 3 Recovery and precision of flavonoid standards in Indonesian Plectranthus amboinicus measured using HPLC-MWD.

\begin{tabular}{lcccccc}
\hline Flavonoid & Recovery $(\%)^{1}$ & RSD $(\%)^{2}$ & Correction factor & Intraday concentrations $(\mu \mathrm{g} / \mathrm{g})^{3}$ & ${\text { RSD }(\%)^{2}}^{\text {RSD }_{\mathrm{H}}(\%)^{4}}$ \\
\hline Apigenin & 43.12 & 3.23 & 2.32 & $562.7 \pm 19.1$ & 3.39 & 6.16 \\
Luteolin & 45.48 & 3.27 & 2.20 & $576.8 \pm 7.0$ & 1.22 & 6.15 \\
Eriodictyol & 14.69 & 4.35 & 6.81 & $4479.0 \pm 56.9$ & 1.27 & 4.14 \\
\hline
\end{tabular}

${ }^{1}$ Results were obtained using an HPLC-MWD in room temperature at $290 \mathrm{~nm}$ for eriodictyol and $340 \mathrm{~nm}$ for apigenin and luteolin. Separation was done using a Reverse-Phase ZORBAX Eclipse XDB-C ${ }_{18}$ column ( $150 \times 4.60 \mathrm{~mm}$ i.d., particle size $\left.5.00 \mu \mathrm{m}\right)$ The mobile phases were $4 \%$ tetrahydrofuran in acetonitrile (mobile phase $\mathrm{A}$ ) and 0.2\% aqueous phosphoric acid (mobile phase $\mathrm{B}$ ) at a ratio of 35:65 (A:B). The flow rate was $1.0 \mathrm{~mL} / \mathrm{min}$ for $15 \mathrm{~min}$. Measurements were performed on $20 \mu \mathrm{L}$ of hydrolyzed dried leaves extract of Indonesian Plectranthus amboinicus spiked with $5.0 \mu \mathrm{g} / \mathrm{mL}$ of apigenin, luteolin, and eriodictyol prior to hydrolysis.

${ }^{2}$ Obtained by the following formula: (SD/mean) $\times 100 \%$.

${ }_{3}^{3}$ Based on dried sample weight, results expressed as mean \pm standard deviation. Measurements were obtained by HPLC analysis on unspiked samples and subsequently multiplied by the correction factors.

${ }^{4}$ Horwitz standard deviation obtained by the following equation: $2^{1-0.5 \log C}$.

using the aforementioned spiked extracts with a working range of $0.5-50.0 \mu \mathrm{g} / \mathrm{mL}$ for apigenin standards, 0.5-25.0 $\mu \mathrm{g} / \mathrm{mL}$ for luteolin standards, and $1.0-50.0 \mu \mathrm{g} / \mathrm{mL}$ for eriodictyol standards. All of the standard curves met the criteria of acceptability for they were all above 0.9900 . The retention times of apigenin were between 6.032-6.283 while those of luteolin were between 3.839-3.963 and those of eriodictyol were between 4.030-4.175 min (Table 2). The responsiveness of the peak areas and to the amount spiked within the sample matrix demonstrates acceptability of the specificity of the method. All of the flavonoids were identified within 10 min due to the length of the column.

The method limit of detection and quantitation was determined by spiking the Indonesian crude extracts with the target analytes at a final concentration that is $5.0 \mu \mathrm{g} / \mathrm{mL}$ or approximately 10 times the LOQi. The method limit of detection was found to be $41.2 \mu \mathrm{g} / \mathrm{g}$ for apigenin, 44.0 $\mu \mathrm{g} / \mathrm{g} \mathrm{dspl}$ for luteolin, and $18.9 \mu \mathrm{g} / \mathrm{g}$ for eriodictyol, while the method limit of quantitation for apigenin, luteolin, and eriodictyol was found to be 137.3, 146.5, and $62.9 \mu \mathrm{g} / \mathrm{g}$ respectively. The retention time and peak area precision were adequate for their respective RSD values were below $2 \%$ and $4 \%$.

The accuracy of the method was determined through the recovery tests, in which the sample extracts were spiked at the same concentrations used for the method limit of detection and quantification tests. At this concentration, or approximately $500 \mu \mathrm{g} / \mathrm{g}$, the recoveries of apigenin, luteolin, and eriodictyol were too low than the criterions of acceptability (Latimer 2012) (see Table 3).
Interestingly, increasing the spiking concentrations led to higher recoveries, with recoveries achieving values that are greater than $75.00 \%$ when the concentration of analytes spiked approximately $5000 \mu \mathrm{g} / \mathrm{g}$ (Figure 6d). Similar results were found when the $\mathrm{HCl}$ concentration was increased to $4 \mathrm{M}$. Through the recovery tests, the correction factors for apigenin, luteolin, and eriodictyol were found to be 2.32, 2.20, and 6.81 respectively. In addition to the low material cost, the advantages of sonication lie with its relatively low temperature range and efficiency compared with other methods in the extraction of flavonoids from leaves (Wang and Weller 2006). However, this method requires a separate hydrolysis steps which in turn was reported to lead to flavonoid decomposition (Koşar et al. 2005). Indeed, the original version of the HPLC method had integrated the extraction and hydrolysis procedure using a reflux which resulted in recoveries close to $100 \%$ for apigenin and luteolin (Haghi and Hatami 2010). Moreover, recovery tests were lacking in the previous study in which the ultrasonic method of extraction and hydrolysis was based on (Lin and Harnly 2007). That being said, the stability of the flavonoid standards at various hydrochloric acid concentrations also creates the possibility that other compounds within the sample matrix contributed to flavonoid degradation.

The intralab repeatability of the method of analysis was found to demonstrate acceptable precision within the same day of testing and within different weeks of testing (Table 2). Overall the results of the method validation tests demonstrated that the method was precise but no accurate 
TABLE 4 Flavonoid quantification and bioactivities of Plectranthus amboinicus samples.

\begin{tabular}{|c|c|c|c|c|c|c|}
\hline \multirow[t]{2}{*}{ Sample } & \multicolumn{3}{|c|}{ Flavonoid concentration $(\mu \mathrm{g} / \mathrm{g})^{1}$} & \multirow[t]{2}{*}{ TFC ( $\mu \mathrm{g} Q \mathrm{QE} / \mathrm{g})$} & \multicolumn{2}{|c|}{$\mathrm{IC}_{50}(\mu \mathrm{g} / \mathrm{mL})^{3}$} \\
\hline & Apigenin & Luteolin & Eriodictyol & & DPPH & AGI \\
\hline Indonesia & $571.7 \pm 11.6^{\mathrm{a}}$ & $584.5 \pm 7.4^{b}$ & $4547.3 \pm 16.5$ & $4146.1 \pm 55.3^{b}$ & $14.4 \pm 1.2^{\mathrm{b}}$ & $1181.9 \pm 113.5^{b}$ \\
\hline Japan & $532.4 \pm 1.8^{b}$ & $1100.6 \pm 5.1^{\mathrm{a}}$ & nd & $7934.0 \pm 0.0^{\mathrm{a}}$ & $24.0 \pm 0.3^{a}$ & $4451.4 \pm 290.0^{a}$ \\
\hline Vitamin C & - & - & - & - & $1.6 \pm 0.3^{c}$ & - \\
\hline Acarbose & - & - & - & - & - & $0.02 \pm 0.001^{c}$ \\
\hline
\end{tabular}

${ }^{1}$ Based on dried sample weight, results expressed as mean and standard deviation of three measurements, values with different letter annotations denote significantly different measurements based on one-way ANOVA ( $p \leq 0.05)$. Results were obtained using an HPLC-MWD in room temperature at $290 \mathrm{~nm}$ for eriodictyol and $340 \mathrm{~nm}$ for apigenin and luteolin. The mobile phases were $4 \%$ tetrahydrofuran in acetonitrile (mobile phase A) and 0.2\% aqueous phosphoric acid (mobile phase B) at a ratio of 35:65 (A:B). Separation was done using a Reverse-Phase ZORBAX Eclipse XDB- $C_{18}$ column $(150 \times 4.60 \mathrm{~mm}$ i.d., particle size $5.00 \mu \mathrm{m})$. The flow rate was $1.0 \mathrm{~mL} / \mathrm{min}$ for 15 min. Measurements were performed on $20 \mu \mathrm{L}$ injections. Final sample solution volume prior to injection $(10 \mathrm{~mL})$ was obtained from $0.5 \mathrm{~mL}$ extracts or equals to $0.05 \mathrm{~g}$ dried leaf weight. nd denotes that the analyte was not detected.

2 TFC denotes total flavonoid content, QE denotes quercetin equivalent., results expressed as mean and standard deviation of three measurements, values with different letter annotations denote significantly different measurements based on one-way ANOVA $(p \leq 0,05)$. Results were inferred using the quercetin calibration curve obtained from colorimetry and based on dried sample weight.

${ }^{3}$ The IC 50 denotes the concentration needed to decrease the concentration of DPPH by $50 \%$ or inhibit $50 \%$ of $\alpha$-glucosidase (AGI) activity. Results were obtained through colorimetry. Different letter annotations denote significantly different measurements based on one-way ANOVA $(p \leq 0.05)$.

due to the low recovery values. Therefore, correction factors were employed to account for this inaccuracy, albeit optimization of the extraction and hydrolysis method is still required.

\subsection{Application of validated HPLC-MWD method on dried Plectranthus amboinicus leaves}

The versatility of the method was investigated by comparing the apigenin, luteolin, and eriodictyol content of dried Indonesian P. amboinicus and Japanese P. amboinicus leaves. In addition to genetical differences, environmental conditions were also reported to impact the production of flavonoids such as apigenin and luteolin. Increased UV-radiation coupled with water stress were reported to induce the accumulation of luteolin-7-O-glucosides and certain apigenin glycosides in plants (Tattini et al. 2004). Indeed, the impact of these factors were observed in the analysis, in which the Japanese leaves had a greater luteolin content when compared to their Indonesian counterparts but the inverse was found for the concentration of apigenin, with concentrations of $1100.6 \pm 5.1$ and $532.4 \pm 1.8$ $\mu \mathrm{g} / \mathrm{g}$ for luteolin and $584.5 \pm 7.4$ and $571.7 \pm 11.6 \mu \mathrm{g} / \mathrm{g}$ for apigenin respectively (Figure 6 and Table 3 ). The reported results had taken into consideration the effect of degradation thereby utilizing the correction factors obtained in the previous subsection. However, the small peak areas relative to others present in the chromatogram indicate that apigenin and luteolin were not major flavonoid constituents of the Indonesian leaves. The differences between the apigenin and luteolin content of the Indonesian leaves for this study and the previous study could be attributed to the different climatic and geographical conditions between Bogor and Tsukuba. As mentioned previously, these factors may significantly alter the efficacy of the plant's phytochemicals and functional properties (Wang et al. 2005).
Interestingly, the presence of eriodictyol was only found in the Indonesian samples, which was supported by the NMR-metabolomics data. Following spiking of the Japanese extracts with apigenin, luteolin, and eriodictyol, the HPLC method was shown to be capable of separating and detecting said analytes in the Japanese sample matrix. This confirms the absence of eriodictyol in the unspiked Japanese samples. Studies on the identification of flavonoids of the plant had reported the presence of eriodictyol albeit the samples used for said studies were from Egypt and South America. Moreover, the aforementioned studies had not quantified nor directly compared the presence of said analyte between samples of different origins (Brieskorn and Riedel 1977; El-Hawary et al. 2012). However, the relatively small peak of eriodictyol in the Indonesian chromatograms indicated that it was not a major flavonoid constituent of the leaves.

\subsection{Crude total flavonoid, DPPH radical scavenging ac- tivity, and $\alpha$-glucosidase assay of dried Plectran- thus amboinicus leaves using spectrophotometer- UV/Vis}

The differences in cultivation conditions of the samples, such as the environment along with genotype could result in a different accumulation of flavonoid glycosides and their aglycones (Mphahlele et al. 2014). Indeed, Japanese $P$. amboinicus had a greater total flavonoid content when compared with its Indonesian counterpart, with concentrations of $7934.0 \pm 0.0$ and $4146.1 \pm 55.3 \mu \mathrm{g} \mathrm{QE} / \mathrm{g}$ dried leaves, respectively (Table 4). Similarly, the Japanese leaves also had higher total flavonoid content than the Indonesian leaves when the $\mathrm{HCl}$ concentration was raised to 4 and $6 \mathrm{M}$ for hydrolysis. The larger peak areas along with greater number of unidentified peaks in the chromatograms of the Japanese leaves also support this finding. That being said, increasing the $\mathrm{HCl}$ concentration de- 
creased the total flavonoid content of both samples, suggesting decomposition.

In order to investigate the possible differences in bioactivities of the Indonesian and Japanese leaves, the antioxidative and antidiabetic properties were explored through DPPH radical scavenging and $\alpha$-glucosidase inhibitory assays. Greater DPPH reduction and $\alpha$ glucosidase inhibition activities were found in Indonesian samples than the Japanese samples, with $\mathrm{IC}_{50}$ values of $14.4 \pm 1.2$ and $24.0 \pm 0.3 \mu \mathrm{g} / \mathrm{mL}$ for the DPPH and 1181.9 \pm 113.5 and $4451.4 \pm 290.0 \mu \mathrm{g} / \mathrm{mL}$ for $\alpha$-glucosidase inhibitory test respectively (Table 4). The lower flavonoid content along with the greater DPPH radical scavenging and $\alpha$-glucosidase inhibitory activities of the Indonesian leaves suggests that these bioactivities might be more influenced by other secondary metabolites such as terpenes and phenolic acids. Indeed, the essential oil of Indian $P$. amboinicus had much greater potency to inhibit $\alpha$ glucosidase, with $\mathrm{IC}_{50}$ less than $30 \mu \mathrm{g} / \mathrm{mL}$ (Govindaraju and Arulselvi 2018). However, the essential oil also had much lower DPPH radical scavenging activity compared with our study (Murthy et al. 2009). This suggests the greater influence of other secondary metabolites, such as phenolic acids, in scavenging DPPH radicals.

\section{Conclusions}

Environmental factors might contribute to the variation of secondary metabolites accumulation in plants and to an extent their potential benefits to health. NMR-based metabolomics conducted in this study showed that, in general, the phytochemical content of P. amboinicus with different geographical origins is quite varied. More targeted analysis revealed that Japanese P. amboinicus had higher total flavonoids content than its Indonesian counterpart. Of the three flavonoids analyzed using a validated HPLC-MWD method, the Japanese samples had the higher amount of lutein but lower amount of apigenin. Eriodyctiol was only found in Indonesian P. amboinicus. However, these samples showed greater DPPH radical scavenging and $\alpha$-glucosidase inhibitory activity compared with the Japanese samples. Apparently, nonflavonoid compounds also play a role in the reported activities, which could be triterpenes. Further research should investigate this possibility.

\section{Aknowledgments}

The authors would like to thank the Ministry of Research Technology and Higher Education of the Republic of Indonesia for funding this research under International Collaboration Competitive Grant No. 1572/IT3.11/PN/2018. We would also like to acknowledge the UNU-KIRIN Fellowship Follow-up Grant for 2016-2018 for partial financial contribution to this study. The authors also extend their appreciation to the Laboratory of Food Analytical Service, Department of Food Science and Technology, Bogor Agricultural University, for providing support in HPLC analysis.

\section{Authors' contributions}

NDY was responsible for NMR data processing, multivariate data analysis and manuscript writing monitoring. MAS conducted targeted analysis with HPLC and bioactivity test and wrote the mansucript. HNL supervised MAS in developing HPLC method and proofread the manuscript before submission. MG and YTI advised about the extraction method and conducted manuscript proofreading before submission. All the author read and approved the final version of the manuscript.

\section{Competing interests}

NDY is on the editorial board of the Indonesian Journal of Biotechnology, and was recused from this article's review and decision. The authors declare no other competing interests.

\section{References}

Andarwulan N, Yuliana ND, Hasna E, Aziz SA, Davis TD, Andarwulan N. 2014. Comparative analysis of three torbangun clones (Plectranthus amboinicus (lour.) spreng) based on phenotypic characteristics and phenolic content. Am J Plant Sci. 5(24):3673-3683. doi:10.4236/ajps.2014.524383.

Arumugam G, Swamy MK, Sinniah UR. 2016. Plectranthus amboinicus (lour.) spreng: Botanical, phytochemical, pharmacological and nutritional significance. Molecules. 21(4):369. doi:10.3390/ molecules21040369.

Brieskorn CH, Riedel W. 1977. Flavonoide aus Coleus amboinicus. Planta Med. 31(04):308-310. doi:10. 1055/s-0028-1097537.

Brieskorn CHRW. 1977. Die Triterpeiisaureii aus Coleus amboiiiicus Loureiro. Arch Pharm. 310:910-916. doi: 10.1002/ardp.19773101108.

Chang CC, Yang MH, Wen HM, Chern JC. 2002. Estimation of total flavonoid content in propolis by two complementary colorimetric methods. J Food Drug Anal. 10(3).

da Silva LAL, Faqueti LG, Reginatto FH, dos Santos ADC, Barison A, Biavatti MW. 2015. Phytochemical analysis of vernonanthura tweedieana and a validated UPLC-PDA method for the quantification of eriodictyol. Rev Bras Farmacogn. 25(4):375-381. doi: 10.1016/j.bjp.2015.07.009.

Damanik R, Wahlqvist ML, Wattanapenpaiboon N. 2006. Lactagogue effects of Torbangun, a Bataknese traditional cuisine. Asia Pac J Clin Nutr. 15(2):267-274.

El-Hawary SS, El-Sofany RH, Abdel-Monem AR, Ashour RS, Sleem AA. 2012. Polyphenolics content and biological activity of Plectranthus amboinicus (lour.) spreng growing in Egypt (Lamiaceae). Pharmacogn J. 4(32):45-54. doi:10.5530/PJ.2012.32.9.

Eriksson L, Byrne T, Johansson E, Trygg J, Vikström C. 2003. Multi- and megavariate data analysis: basic principles and applications. volume 1. Umeå: Umetrics Academy. 
Govindaraju S, Arulselvi PI. 2018. Characterization of Coleus aromaticus essential oil and its major constituent carvacrol for in vitro antidiabetic and antiproliferative activities. J Herbs Spices Med Plants. 24(1):37-51. doi:10.1080/10496475.2017.1369483.

Haghi G, Hatami A. 2010. Simultaneous quantification of flavonoids and phenolic acids in plant materials by a newly developed isocratic high-performance liquid chromatography approach. J Agric Food Chem. 58(20):10812-10816. doi:10.1021/jf102175x.

Hameed A, Hafizur RM, Hussain N, Raza SA, Rehman M, Ashraf S, Ul-Haq Z, Khan F, Abbas G, Choudhary MI. 2018. Eriodictyol stimulates insulin secretion through cAMP/PKA signaling pathway in mice islets. Eur J Pharmacol. 820:245-255. doi:10.1016/j.ejphar.2017. 12.015.

Koşar M, Dorman H, Hiltunen R. 2005. Effect of an acid treatment on the phytochemical and antioxidant characteristics of extracts from selected Lamiaceae species. Food Chem. 91(3):525-533. doi:10.1016/j. foodchem.2004.06.029.

Latimer GW, editor. 2012. Official methods of analysis of AOAC International. AOAC International.

Lin LZ, Harnly JM. 2007. A screening method for the identification of glycosylated flavonoids and other phenolic compounds using a standard analytical approach for all plant materials. J Agric Food Chem. 55(4):1084-1096. doi:10.1021/jf062431s.

Lin LZ, Mukhopadhyay S, Robbins RJ, Harnly JM. 2007. Identification and quantification of flavonoids of Mexican oregano (Lippia graveolens) by LC-DADESI/MS analysis. J Food Compos Anal. 20(5):361369. doi:10.1016/j.jfca.2006.09.005.

Lukhoba CW, Simmonds MSJ, Paton AJ. 2006. Plectranthus: a review of ethnobotanical uses. J Ethnopharmacol. 103(1):1-24. doi:10.1016/j.jep.2005.09.011.

Mediani A, Abas F, Khatib A, Maulidiani H, Shaari K, Choi YH, Lajis N. 2012. ${ }^{1}$ H-NMR-based metabolomics approach to understanding the drying effects on the phytochemicals in Cosmos caudatus. Food Res Int. 49(2):763-770. doi:10.1016/J. FOODRES.2012.09.022.

Mphahlele RR, Stander MA, Fawole OA, Opara UL. 2014. Effect of fruit maturity and growing location on the postharvest contents of flavonoids, phenolic acids, vitamin $\mathrm{C}$ and antioxidant activity of pomegranate juice (cv. Wonderful). Sci Hortic. 179:36-45. doi:10.1016/ j.scienta.2014.09.007.

Murthy PS, Ramalakshmi K, Srinivas P. 2009. Fungi- toxic activity of Indian borage (Plectranthus amboinicus) volatiles. Food Chemistry. 114(3):1014-1018. doi:10.1016/J.FOODCHEM.2008.10.064.

Salazar-Aranda R, Pérez-López LA, Joel LA, AlanísGarza BA, Waksman de Torres N. 2011. Antimicrobial and antioxidant activities of plants from northeast of mexico. J Evidence-based Complementary Altern Med. 2011:1-6. doi:10.1093/ecam/nep127.

Shibano M, Kitagawa S, Nakamura S, Akazawa N, Kusano G. 1997. Studies on the constituents of Broussonetia species. II. Six new pyrrolidine alkaloids, broussonetine $\mathrm{a}, \mathrm{b}, \mathrm{e}, \mathrm{f}$ and broussonetinine $\mathrm{a}$ and $\mathrm{b}$, as inhibitors of glycosidases from Broussonetia kazinoki Sieb. Chem Pharm Bull. 45(4):700-705. doi: 10.1248/cpb.45.700.

Tattini M, Galardi C, Pinelli P, Massai R, Remorini D, Agati G. 2004. Differential accumulation of flavonoids and hydroxycinnamates in leaves of Ligustrum vulgare under excess light and drought stress. New Phytol. 163(3):547-561. doi:10.1111/j. 1469-8137.2004.01126.x.

Viswanathaswamy AHM, Koti BC, Gore A, Thippeswamy AHM, Kulkarni RV. 2011. Antihyperglycemic and antihyperlipidemic activity of Plectranthus amboinicus on normal and alloxaninduced diabetic rats. Indian J Pharm Sci. 73(2):139145. doi:10.4103/0250-474x.91572.

Wang L, Weller CL. 2006. Recent advances in extraction of nutraceuticals from plants. Trends Food Sci Technol. 17(6):300-312. doi:10.1016/j.tifs.2005.12.004.

Wang M, Lamers RJAN, Korthout HAAJ, Van Nesselrooij JHJ, Witkamp RF, Van Der Heijden R, Voshol PJ, Havekes LM, Verpoorte R, Van Der Greef J. 2005. Metabolomics in the context of systems biology: bridging traditional Chinese medicine and molecular pharmacology. Phytother Res. 19(3):173-182. doi:10.1002/ptr.1624.

Yuliana ND, Khatib A, Choi YH, Verpoorte R. 2011a. Metabolomics for bioactivity assessment of natural products. Phytother Res. 25(2):157-169. doi:10.1002/ ptr.3258.

Yuliana ND, Khatib A, Verpoorte R, Choi YH. 2011b. Comprehensive extraction method integrated with NMR metabolomics: a new bioactivity screening method for plants, adenosine A1 receptor binding compounds in Orthosiphon stamineus Benth. Anal Chem. 83(17):6902-6906. doi:10.1021/ac201458n. 